\title{
АРТЕФАКТЫ ЛИЧНОЙ БЕЗОПАСНОСТИ В СУБЪЕКТНОМ ПРОСТРАНСТВЕ СТУДЕНТОВ ВУЗА
}

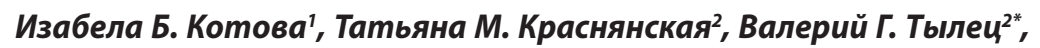 \\ Валерия Г. Веселова ${ }^{2}$, Владимир В. Иохвидов² \\ 1 Пятигорский государственный университет, г. Пятигорск, Российская \\ Федерация \\ 2 Филиал Ставропольского государственного педагогического института \\ в г. Ессентуки, г. Ессентуки, Российская Федерация \\ *E-mail: tyletsvalery@yandex.ru
}

Статья посвящена изучению отношения студентов вуза к использованию амулетов, талисманов и оберегов в качестве артефактов безопасности. Под артефактами безопасности понимаются материально оформленные символы, использование которых предполагает повышение эффективности самообеспечения безопасности. Установлено, что рассматриваемые артефакты входят в систему субъектных представлений студентов вуза и характеризуются верой в свою эффективность в качестве средств обеспечения защиты и благополучия человека. Данная вера опирается на укорененном в культурном пространстве понимании предназначения амулетов, талисманов и оберегов. Данная вера носит в большей степени характер социальной традиции, лишь частично предполагая собственный опыт или магическую направленность личности испытуемых.

Наиболее атрибутируемой среди студентов сферой действия рассматриваемых артефактов выступила защита, отмечается также их способность приносить успех и счастье. Наряду с этим, зафиксирована значительная синкретичность представлений студентов о сущности и функциональности артефрактов безопасности. Их успешная дифференциация основывается на различении происхождения и частично - характера силы. Вне зависимости от присутствия веры в артефакты безопасности, подавляющая часть студентов обнаружила готовность к их применению в настоящем и, особенно, в будущем времени. Рост декларируемой востребованности артесактов безопасности в будущем времени студенты связывают со своим желанием обеспечить защищенность детей. Выделены и проинтерпретированы две группы противоречий: между декларируемой верой в действенность артефактов безопасности и обнаруживаемой готовностью субъектов к их использованию; между заявленной готовностью к текущему использованию артефактов безопасности и реальным их использованием в настоящем времени. 
Ключевые слова: безопасность, психологическая безопасность, самообеспечение безопасности, оберег, амулет, талисман, артефакт, символ, ритуал, вера.

Для цитирования: Котова И. Б., Краснянская Т. М., Тылец В. Г., Веселова В. Г., Иохвидов В. В. Артефакты личной безопасности в субъектном пространстве студентов вуза // Российский психологический журнал. - 2016. - Т. 13. - № 4. - С. 51-67.

Материалы статьи получены 08.07.2016

UDC 159.9.072

doi: 10.21702/rpj.2016.4.3

\title{
ARTIFACTS OF PERSONAL SAFETY IN THE SUBJECT SPACE OF STUDENTS OF THE INSTITUTE OF HIGHER EDUCATION
}

\author{
Izabela B. Kotova', Tat'yana M. Krasnyanskaya', Valerii G. Tylets², \\ Valeriya G. Veselova ${ }^{2}$, Vladimir V. Iokhvidov ${ }^{2}$ \\ ${ }^{1}$ Pyatigorsk State University, Pyatigorsk, Russian Federation \\ 2 Yessentuki Branch, Stavropol State Pedagogical Institute, Yessentuki, Russian \\ *Correspondence author. E-mail: tyletsvalery@yandex.ru
} Federation

The article deals with the study of the relation of students of institutes of higher education to the use of amulets, talismans, and charm as artifacts of safety. Artifacts of safety are material symbols the use of which involves improving the efficiency of self-safety. The considered artifacts entered into the system of subjective views of students; they believed in their effectiveness as means of defense and well-being of the person. The understanding of the purpose of amulets, talismans, and charms, established in the cultural space, formed the basis of this belief. This belief is rather a kind of social tradition; it presupposes own experience or magical orientation of the personality of the respondents only partially.

Defense was the most attributive sphere of activity of the considered artifacts; they also could bring success and happiness. The study showed significant syncretism of students' representations of the nature and functionality of the artifacts of safety. Their successful differentiation was based on the discrimination of origin and the nature of force. Despite the presence of the belief in the artifacts of safety, the overwhelming majority of the students were ready to use them in the present and especially in the future. The students explained the demand for the artifacts of safety in the future by the desire to ensure the protection of children. The authors distinguished and interpreted two groups of contradictions: (a) between the declared 


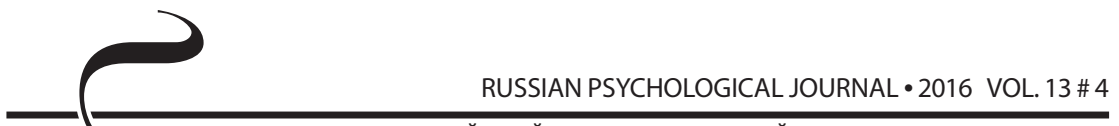

РОССИЙСКИЙ ПСИХОЛОГИЧЕСКИЙ ЖУРНАЛ • 2016 ТОМ 13 № 4

belief in the efficacy of the artifacts of safety and the subjects' willingness to use them; (b) between the declared willingness to use the artifacts of safety and their actual use at the present time.

Keywords: safety, psychological safety, self-safety, charm, amulet, talisman, artifact, symbol, ritual, belief.

For citation: Kotova I. B., Krasnyanskaya T. M., Tylets V. G., Veselova V. G., lokhvidov V. V. Artefakty lichnoi bezopasnosti v sub"ektnom prostranstve studentov vuza [Artifacts of personal safety in the subject space of students of the institute of higher education]. Rossiiskii psikhologicheskii zhurnal - Russian Psychological Journal, 2016, V. 13, no. 4, pp. 51-67.

Original manuscript received 08.07.2016

\section{Введение}

Безопасность как ключевая реальность вызывает по отношению к себе на социальном и научном уровнях устойчивый интерес, приобретший в силу ряда объективных обстоятельств (увеличение средовой и темпоральной неопределенности, расширение спектра угроз, возрастание цены сбоев безопасности и т. д.) характер, особо актуальный на сегодняшний день. Междисциплинарное обращение к ее проблематике позволило раскрыть философские, политические, экономические, социальные, криминологические, педагогические и психологические аспекты нарушения, восстановления и сохранения безопасности объектов и субъектов разной природы в широком контексте бытийного функционирования. Неизменное попадание человека в причинно-следственную феноменологию безопасности в качестве ключевого звена выводит ее психологический аспект в категорию приоритетного рассмотрения. Психологическая безопасность постулируется ведущим фактором безопасности построения, функционирования и совершенствования любого процесса, каждой сложной системы и образования, предусматривающего участие в нем субъекта любого качества и комплекса характеристик [17].

Психологические аспекты безопасности в настоящее время изучаются применительно к образовательным, организационным, политическим, информационным и иным процессам. Рассмотрено влияние на их реализацию субъектов профессиональной, учебной, трудовой, спортивной и бытовой деятельности [1, 3, 7, 15]. Выявлялись ресурсные основания безопасности, принципы, стратегии и сценарии построения связанной с решением ее задач поведенческой активности субъекта $[4,5,12,13]$. Проведенные исследования позволили конкретизировать содержание, закономерности и механизмы обеспечения безопасности $[1,6,11,14]$. Полученные результаты создали 
теоретико-эмпирическую базу, необходимую для расширения предметных интересов в соответствующей предметной области.

Психологическая безопасность в целом интерпретируется как субъектный феномен, который в качестве особой проекции объективных условий жизнедеятельности на психические структуры человека отражает целостность сохранения им состояния защищенности и неснижающейся во времени способности к развитию в направлении жизненно значимой цели личности (Е. М. Благодырь, А. С. Ковдра, Т. М. Краснянская, Н. П. Татьянченко, В. Г. Тылец, А. Д. Тырсикова и др.) $[1,4,6,12,13]$. В качестве основы достижения (обеспечения и самообеспечения) данной проекции безопасности неявно позиционируются используемая субъектом информация и его индивидуально-личностные особенности, определяющие успешность этого процесса $[4,10,12,18]$. Вне зависимости от расставляемых при обращении к данному феномену акцентов основным механизмом психологической безопасности обозначается подконтрольность субъекту комплекса внешних и внутренних факторов, значимых для сохранения им целостности состояния защищенности и неснижающейся во времени способности к развитию [19]. Данная подконтрольность основывается на обладании некоторыми информационными и личностными ресурсами, которые могут обнаруживать очевидную (реальную) или скрытую (виртуальную) природу. Виртуальные ресурсы, не попадая в арсенал актуально доступных для использования средств самообеспечения безопасности, способны приобрести такую возможность по итогам реализации специальных поведенческих актов, имеющих форму ритуалов, обрядов, традиций $[5,6,11]$. Усиление их действия предполагает привлечение артефактов безопасности.

Под артефактами безопасности нами понимаются некоторые предметно оформленные символы, способные при определенных условиях актуализировать и стимулировать направленное привлечение ресурсов поддержания подконтрольности субъекту факторов, значимых для его психологической безопасности. В качестве таких предметно оформленных символов наибольшее распространение в повседневной практике получили амулеты, талисманы и обереги.

Амулеты, талисманы и обереги относятся к этнокультурному наследию человечества, дошедшему до современности из глубины веков в качестве одной из составляющих быта различных народов. Выполняя объединяющую роль вещей-хранителей, они рассматриваются с позиции возможной магической защиты своего обладателя от действия определенных негативных факторов или увеличения эффективности некоторых благоприятных для него воздействий. Свойственные данным артефактам различия прослеживаются по происхождению и приписываемым им традицией оттенкам 
функциональности. Вне зависимости от присущих им различий, своим существованием рассматриваемые артефакты соединяют воедино социальное и индивидуальное, опыт предшественников и надежды современников. Органично вплетаясь в жизнь человека, они способны позитивно или негативно повлиять на организацию ее частного, во многом закрытого от посторонних лиц пласта.

\section{Актуальность исследования}

Нуждаясь в безопасности как гаранте воспроизводства достаточных возможностей для выживания, самореализации и развития, человек не всегда способен ее обеспечить имеющимися у него силами. В силу этого он вынужден прибегать к различным средствам повышения вероятности воспроизводства своей безопасности.

Артефакты безопасности образуют значительную группу материально представленных средств решения задач подобного рода. Обладание ими связано с установлением некоторой (условной, вероятностной) связи с неактуализированными в повседневности и скрытыми от когниции ресурсами безопасности. Их привлечение предполагает создание условий получения в значимый для субъектов момент неверифицируемой ранее помощи от неявно существующих, нелокализованных и неструктурированных сил. Артефакты такого рода не только придают статус очевидности виртуальным ресурсам, но и усиливают, и концентрируют их на достижение востребованной субъектом текущей или перспективной цели в сфере безопасности.

Вместе с тем, использование артефактов безопасности как элемента ранней культуры человечества с ее развитием привело к определенным энтропийным процессам. Изменение культурного пространства и мироощущения человека сопровождалось потерей значительной части объяснительной и нормативной базы привлечения артефактов безопасности. Утрата ритуальных «корней», смешение дифференцирующих признаков, получение мистической окраски, образуя неполный список последствий информационной «размытости» практики использования артефактов безопасности, обеспечили существенное снижение уровня ее эффективности. Утрата культуры применения артефактов безопасности сузила для человека инструментальную базу самообеспечения безопасности. Основу соответствующей практики составили его актуальные ресурсы, представленные индивидуально-психологическими особенностями и способностями воспринимать опасность и выстраивать на нее ответное поведение с большей или меньшей успешностью.

Данные характеристики человека в современной психологии подверглись достаточно пристальному изучению. Анализ источниковой базы по проблеме 
показал, что к настоящему времени установлена связь безопасности с их широким спектром: субъектными представлениями (Н. А. Лызь, Ж. Г. Куповых, S. Brand, R. D. Felner, A. Seitsinger, A. Burns, N. Bolton, M. A. Griffin, A. Neal, E. Siemsen, A. V. Roth, S. Balasubramanian, G. Anand и др.) $[8,14,18,20]$; познавательными способностями (Н. П. Татьянченко) [12]; сензитивностью [9]; способностью к психической саморегуляции (А. Д. Тырсикова и др.) [13]; временной перспективой личности (А. С. Ковдра) [4]; социально-психологическими характеристиками субъекта (М. А. Кудака, О. М. Иллензеер, А. Carmeli, D. Brueller, J. E. Dutton, S. E. Goldstein, A. Young, C. Boyd и др.) [7, 15, 17]. В связи с проблемой психологической безопасности изучались особенности ценностной сферы человека (С. И. Галяутдинова, Е. В. Ахмадеева, Р. Б. Гумерова, S. Clarke) [2, 16], уверенность личности в себе (Д. Д. Саввичева) [10], ее адаптивность, стрессоустойчивость (Н. П. Татьянченко) [12], субъектные стратегии (А. Д. Тырсикова) [13] и т. д. Показав связь с психологической безопасностью практически всех структур личности, данные исследования уже своей множественностью продемонстрировали сохранение потребности поиска особых для нее ресурсных оснований. Ситуация массированной угрозы психологической безопасности требует столь же объемного прироста ресурсов ее локализации и нейтрализации. Источники и механизмы достижения такого прироста в настоящее время остаются еще мало изученными. Наиболее близкими к данной проблематике явились исследования, посвященные психологическим аспектам использования ритуалов (Т. М. Краснянская) [5], а также примет и обычаев безопасности (Т. М. Краснянская, В. Г. Тылец, О. В. Сарма) $[5,6,11]$. Психологические аспекты использования амулетов, талисманов и оберегов в качестве артефактов безопасности до сих пор не попадали в центр научных интересов психологов. Причина этому нам видится в неочевидности связи их использования с фактом и с модальностью наступающих последствий. Позиционирование человеческого фактора аттрактором и амплификатором этой неочевидной связи позволяет включить ее в поле исследовательских и практических интересов психологической науки. Начальный шаг в разработке данной проблематики нами увязан с выявлением роли субъективного фактора в использовании артефактов безопасности.

\section{Организация и методы исследования}

Исследование проводилось на выборке студентов бакалавриата филиала Ставропольского государственного педагогического института в г. Ессентуки. Выбор испытуемых обусловлен, с одной стороны, достижением этим возрастом достаточной зрелости мировоззренческой сферы личности, с другой стороны, особой позицией, занимаемой студентами в социальном пространстве, и открывающимися перед ними в этой связи перспективами. 
В исследовании на добровольной основе приняли участие 220 человек в возрасте от 18 до 22 лет. Выборку образовали 182 (82,7\%) девушки и 38 (17,3\%) юношей. Примерно в равной пропорции в нее вошли городские ( $n=106$, т. е. $48,2 \%)$ и сельские ( $n=114$, т. е. 51,8\%) жители. По национальному составу испытуемые распределились следующим образом: 126 человек (57,3\%) обозначили себя как принадлежащих к славянской национальной группе, 94 человека (42,7\%) - к другим национальным группам. Таким образом, выборка, в целом, отражает структуру молодежи, обучающейся в гуманитарном вузе региона. Она рассматривается нами в качестве однородной выборки студентов вуза.

Отсутствие известных методик для изучения обозначенной проблематики обусловило наше обращение к исследовательским возможностям методов описательной психологии. В качестве основного метода получения информации о различных аспектах отношения испытуемых к артефактам безопасности выступило написание эссе. Выбор метода основан на том, что позволяя отойти от жестких рамок трансляции информации, эссе дает субъекту возможность высказать то, что представляется ему наиболее важным по поднятому вопросу, и в том оформлении, которое в наибольшей мере способствует выражению им своего отношения к излагаемому сообщению.

Для сбора исследовательской информации испытуемым было предложено написать эссе на тему «Роль амулетов, талисманов и оберегов в моей жизни». Придавая выполнению задания большую целенаправленность, мы проинструктировали их о необходимости раскрытия в эссе своего понимания особенностей этих артефактов, их назначения и эффективности. Было указано на желательность иллюстрации высказываемой позиции примерами из собственной жизни, жизни близких людей и знакомых.

Метод написания эссе был дополнен беседой, позволяющей уточнить высказанные в нем авторские позиции, и наблюдением, направленным на фиксацию невербальных признаков отношения испытуемых к практике использования амулетов, талисманов и оберегов.

Для анализа информации были привлечены возможности экспертного метода. В качестве экспертов выступили 5 преподавателей вуза, имеющих опыт проведения и оценки эссе. Работа экспертов проводилась на автономной основе. Экспертам было предложено проанализировать материалы, собранные на выборке, по нескольким параметрам и критериям. В их состав вошли: 1) вера испытуемых в действенность рассматриваемых артефактов (абсолютная/избирательная/отрицание; реалистичная/привычная/ магическая); 2) опыт подтверждения действенности артефактов (свой/чужой, непрерывный/эпизодический); 3) сфера атрибутируемой действенности (защита/успех/счастье); 4) различение артефактов (адекватно/синкретично/ 
ошибочно); 5) готовность использовать артефакты (в настоящем/в будущем/ ситуативно); 6) использование артефактов (нет/ситуативное/постоянное). Выбор параметров и критериев оценки осуществлялся по итогам обсуждения на подготовительном этапе с группой студентов $(\mathrm{n}=20)$ практики использования артефактов безопасности.

Интерпретация итоговых результатов исследования основывалась на доминирующей позиции экспертов. Для обеспечения содержательности интерпретации привлекались также данные собственного изучения собранного материала.

\section{Результаты исследования}

Наблюдение за испытуемыми в ходе подготовки эссе показало, что ни один из них не остался равнодушным к обсуждению вопроса использования амулетов, талисманов и оберегов. Был продемонстрирован очевидный интерес к выполнению задания. Все испытуемые обнаружили понимание проблематики и сформированность в отношении нее собственного мнения. Невербальные признаки поведения позволили сделать вывод об обладании всеми студентами, вошедшими в состав эмпирической выборки, некоторыми представлениями о причинном поле и действенности включения в жизнь амулетов, талисманов и оберегов.

Содержательный анализ выполненного эссе показал неравномерность распределения студентов по вере в действенность рассматриваемых артефактов. Крайних позиций придерживается меньшая часть испытуемых: абсолютная вера в них была зафиксирована всего лишь у 32 (14,5\% от всей выборки), полное ее отрицание - у 29 (13,2\%) испытуемых. Избирательная вера в возможности амулетов, талисманов и оберегов проявлена 149 (67,7\%) испытуемыми. Таким образом, 191 человек $(86,8 \%)$ из состава выборки студентов в той или иной мере верит в действенность рассматриваемых артефактов как инструментов оказания некоторого содействия в построении жизнедеятельности человека. По итогам применения критерия $\varphi^{*}$ Фишера установлена статистическая достоверность $(\mathrm{p} \leq 0,001)$ различий между выборками студентов, обладающих и не обладающих такой верой. Данный результат позволяет признать достаточно значительную укорененность среди студентов представлений о результативности использования в своей жизни амулетов, талисманов и оберегов.

Дальнейшее выявление характера веры в артефакты у ее обладателей привело к установлению того, что для большинства из них ( $\mathrm{n}=116$, т. е. 60,7\% здесь и далее от выборки объемом 191 человек) она является чем-то привычным, «само собой разумеющимся», т. е. является, по сути, органичной частью культуры повседневности. Испытуемые с таким восприятием 
рассматриваемых артефактов, объясняя свою веру в них, преимущественно отмечали, что «всем это известно», «это очевидно» и «так было всегда». Небольшая, по сравнению с первой группой, согласно критерию $\varphi^{*}$ Фишера $\mathrm{p} \leq 0,001$, часть студентов ( $\mathrm{n}=58$, т. е. 30,4\%), поясняя происхождение своей веры в амулеты, талисманы и обереги, привела факты их результативности, основанные на некоторых событиях из своей жизни, жизни своих родителей и знакомых людей. Остальные студенты подвыборки ( $\mathrm{n}=17$, т. е. 8,9\%) в своих эссе четко указали, что рассматриваемые артефакты обладают магической, необъяснимой силой, позволяющей человеку решить свои проблемы. Соответственно, только у $30,4 \%(n=58)$ испытуемых изучаемая вера основывается на некоторых реально произошедших событиях, которые подтвердили действенность амулетов, талисманов и оберегов. У остальных $69,6 \%(n=133)$ она не основывается на чем-либо реалистичном и носит, по сути, иррациональный характер, «подпитывающийся» окружающими их социокультурными представлениями и стереотипами. Основываясь на результатах применения критерия $\varphi^{*}$ Фишера, можно признать, что выявленное преобладание носит статистически достоверный характер ( $\leq \leq 0,001)$ и может обнаруживаться с высоким уровнем вероятности.

Изучение материалов эссе студентов ( $\mathrm{n}=58)$, обнаруживших веру в амулеты, талисманы и обереги, основанную на фактах подтверждения их эффективности, позволило установить, что собственным опытом такого рода обладает только 22 человека (37,9\%), остальные 36 человек $(62,1 \%)$ уверенность в эффективности рассматриваемых артефактов основывают на событиях из жизни своих родителей и знакомых людей. При этом постоянное подтверждение эффективности артефактов из 58 студентов смогли отметить только 12 человек (20,7\%), остальные 46 человек (79,3\%) обозначали его как эпизодическое, часто единичное, явление. Согласно полученным результатам, непрерывное воспроизведение результативности использования амулетов, талисманов и оберегов отмечает минимальная часть всей выборки студентов. Таким образом, на уровне статистической тенденции $\left(\varphi_{\text {эмп }}^{*}=1,81, \mathrm{p}=0,035\right)$ в группе студентов могут не найтись лица, на собственном опыте получившие подтверждение результативности амулетов, талисманов и оберегов. Несмотря на данное обстоятельство, подавляющее большинство студентов сохраняет веру в действенность данных артефактов.

С учетом того, что взаимодействие со студентами, обозначившими отсутствие веры в амулеты, талисманы и обереги, показало, что они обладают представлениями об их назначении, изучение сферы атрибутируемой данным предметам действенности проводилось на полной исследовательской выборке. Было установлено, что подавляющая часть выборки ( $\mathrm{n}=206$, т. е. 93,6\%) увязывает использование названных артефактов с защитой, 
т. е. на статистически достоверном уровне $\left(\varphi_{\text {эмп }}^{*}=7,67, \mathrm{p} \leq 0,001\right)$ преобладает уверенность в их способности предотвратить для своего обладателя наступление нежелательных событий (несчастного случая, болезни, увечья, «сглаза»). Значительно меньшая часть выборки студентов согласовывает использование амулетов, талисманов и оберегов также с достижением успеха ( $n=55$, т. е. $25,0 \%)$ и счастья ( $n=34$, т. е. $15,5 \%$ ). Беседа с испытуемыми данной группы показала, что действие артефактов безопасности увязывается испытуемыми, с одной стороны, с энергетической подпиткой своего обладателя (что более свойственно, по их мнению, талисманам и оберегам), с другой стороны, с гармонизацией пространства его жизнедеятельности (что больше относится к действию амулетов). В целом, амулеты, талисманы и обереги в представлениях студентов с высокой вероятностью (близкой к 95,0\%) наделяются защитной функцией и, соответственно, могут рассматриваться в качестве артефактов безопасности. Более того, приписывание им функции обеспечения благополучия лежит в русле расширенного понимания безопасности, как феномена, отражающего не только защищенность, но и сохранение способности субъекта к развитию в направлении жизненной цели личности.

Анализ содержания эссе позволил прийти к выводу, согласно которому только часть студентов ( $n=64$, т. е. $29,1 \%$ ) осуществляет адекватную дифференциацию рассматриваемых артефактов. Она была проведена, преимущественно, по происхождению. Испытуемыми, проявившими компетентность в этой сфере, отмечалось то, что талисманы и обереги целенаправленно создаются конкретным лицом, сведущим в соответствующей практике (в первом случае - близким человеком, во втором случае - магом, специализирующимся в данном виде деятельности), для передачи субъекту, нуждающемуся в содействии в построении некоторой сферы своей активности. Статус амулета, как они отмечали, предмет получает по итогам индивидуального опытного подтверждения своей действенности в значимых для субъекта типах ситуаций. Единицы смогли выделить различия между рассматриваемыми артефактами по способу функционирования: талисманы и обереги были наделены донорской функцией, а амулеты - функцией гармонизации определенной сферы жизнедеятельности конкретного субъекта, имеющей проблемы безопасности. Достаточно значительная часть студентов обнаружила синкретичность ( $\mathrm{n}=103$, т. е. 46,8\%) или ошибочность ( $\mathrm{n}=53$, т. е. $24,1 \%$ ) определения амулетов, талисманов и оберегов. Таким образом, подавляющая часть испытуемых ( $\mathrm{n}=156$, т. е. $70,9 \%)$ не владеет адекватной информацией о сущности и особенностях функционирования амулетов, талисманов и оберегов. Такие студенты на статистически достоверном уровне $\left(\varphi_{\text {эмп }}^{*}=5,81, \mathrm{p} \leq 0,001\right)$ преобладают над информированными студентами. Вместе с тем, как установлено, большая часть подвыборки таких 
студентов ( $\mathrm{n}=151$, т. е. 96,8\% от $\mathrm{N}=156$ ) верит в их действенность. Среди студентов, владеющих адекватной информацией об амулетах, талисманах и оберегах, такой верой обладают только 40 человек (62,5\% от $\mathrm{N}=64)$. Соответственно, информированность не может рассматриваться обязательным основанием веры в действенность артефактов безопасности.

Было также установлено, что подавляющая часть испытуемых ( $\mathrm{n}=202$, т. е. 91,8\% всей выборки) обладает готовностью к использованию артефактов безопасности. Данную готовность проявили не только все студенты, которые верят в их действенность (191 человек), но и часть студентов (11 человек), которые отрицают обладание такой верой. Обнаружение готовности к использованию рассматриваемых артефактов, вопреки декларации отсутствия веры в их действенность, может указывать на наличие у субъектов скрытой надежды в существование ожидаемых эффектов. Кроме того, данное противоречие может обнаруживать их нежелание демонстрировать веру в феномены, не получившие на сегодняшний день официального признания, и остаться, соответственно, в рамках научной парадигмы. Из всей выборки только 18 человек (8,2\%) обозначили отсутствие своей готовности к использованию амулетов, талисманов и оберегов. Отсутствие веры в действенность рассматриваемых артефактов, как аргумент в пользу отказа, эти студенты подкрепляли признанием своей некомпетентности в соответствующей сфере. Несмотря на имеющиеся исключения, следует признать, что большая часть студентов потенциально готова использовать артефакты безопасности в процессе своей жизнедеятельности, даже, порой, вопреки своей уверенности относительно их действенности.

Уточнение условий готовности к использованию артефактов безопасности показало, что она распространяется: на настоящее время у 162 человек $(80,2 \%$ от $\mathrm{N}=202)$, на будущее время - у 188 человек (93,1 \% от $\mathrm{N}=202)$, на наступление необходимой ситуации - у 192 человек (95,0\% от $\mathrm{N}=202)$. Таким образом, значительная часть студентов готова использовать артефакты безопасности во всех временах своей жизни. Анализ содержания эссе показал, что прирост готовности к использованию артефактов безопасности образуется на основе направленности обеспечивать таким образом защиту своим будущим детям, которые, по мнению многих испытуемых, в ней особенно нуждаются. Кроме того, наступление трудных, напряженных и опасных ситуаций является для студентов решающим фактором для обращения к потенциалу артефактов безопасности.

Изучение практики реального использования различных артефактов безопасности позволило установить, что она охватывает только 124 человека (т. е. 56,4\% от всей выборки студентов и 76,5\% от численности студентов, обозначивших готовность к применению артефактов в настоящем времени). 
Этим обнаруживается статистическая тенденция к совпадению готовности к применению и реального применения рассматриваемых артефактов ( $p \leq 0,05)$. Студенты, использующие артефакты безопасности, чаще всего к ним относили нательный крестик, который наделялся интегративной функцией защиты и обеспечения своего благополучия. Обнаруженное расхождение между заявленной готовностью к использованию и реальным использованием в настоящем времени амулетов, талисманов и оберегов студенты обосновали отсутствием у них на текущий момент нужных артефактов безопасности.

Таким образом, эмпирическая часть исследования позволила не только обозначить особенности субъектной позиции студентов вуза в отношении использования амулетов, талисманов и оберегов. Она способствовала также выявлению двух противоречий: между верой в действенность артефактов и готовностью к их использованию, между декларируемой готовностью к использованию артефактов и их реальным использованием. Данные противоречия также отражают особенности субъектного отношения к практике привлечения артефактов безопасности.

\section{Выводы}

Проведенное исследование позволило охарактеризовать особенности восприятия студентами вуза амулетов, талисманов и оберегов в качестве артефактов безопасности личности. Данные артефакты безопасности, увязываясь на субъективном уровне со способностью человека обеспечивать свою защищенность и определенный уровень благополучия, органично входят в жизненное пространство значительной части студентов вуза. В основе позитивного отношения к данным артефактам лежит сформированность у них достаточно устойчивой веры в действенность амулетов, талисманов и оберегов в практике самообеспечения безопасности. Данная вера носит, преимущественно, избирательный характер, основанный на привычном отношении к предметам с соответствующим статусом. Абсолютная вера в магическую силу амулетов, талисманов и оберегов среди студентов носит единичный характер. Столь же единичной является для них вера в силу этих предметов на основе собственного опыта. Кроме того, зафиксирована утрата значительной частью выборки опыта адекватной дифференциации амулетов, талисманов и оберегов. Несмотря на это, подавляющая часть студентов готова использовать артефакты безопасности не только в настоящем, но и в будущем. Рост данной готовности в отношении будущего связывается с потребностью обеспечить большую защищенность и благополучие своего потомства.

Исследование привело к установлению двух типов противоречий в субъектном отношении студентов к использованию артефактов безопасности. 


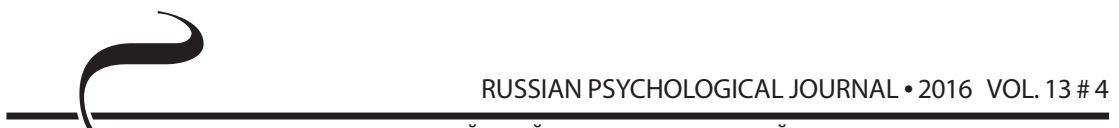

РОССИЙСКИЙ ПСИХОЛОГИЧЕСКИЙ ЖУРНАЛ • 2016 ТОМ 13 № 4

Одно из них состоит в обнаружении готовности к использованию амулетов, талисманов и оберегов при декларации отсутствия веры в их действенность, другое - в заявлении готовности использовать данные предметы при их фактическом неиспользовании на текущий момент. Их причину мы видим, с одной стороны, в существовании надежды на действенность артефактов безопасности, перешедшей на уровень подсознания, с другой стороны, в желании презентовать себя в качестве сторонника научной картины мира. Можно сделать вывод, что при наступлении определенных обстоятельств (угроза здоровью, жизни, успеху, благополучию и т. п.) студенты, даже не вполне ориентирующиеся в особенностях практики использования артефактов безопасности, готовы обратиться к их возможностям. Таким образом, амулеты, талисманы и обереги могут рассматриваться в качестве средств активизации и концентрации виртуальных ресурсов безопасности человека. Снизить эффективность обращения к их возможностям может утрата значительной частью респондентов культуры применения амулетов, талисманов и оберегов в практике жизнедеятельности.

Изложенные в статье эмпирические данные и сделанные на их основе выводы и обобщения рассматриваются нами в качестве начального вклада в разработку новой психологической проблематики. Она может быть продолжена, в частности, в исследовании, характеризующем особенности представленности артефактов безопасности в субъектном опыте студентов, принадлежащих к различным социальным группам.

\section{Литература}

1. Благодырь Е. М. Психологические особенности формирования безопасного поведения у воспитанников детских домов: дисс. ... канд. психол. наук. - Пятигорск: ПГЛУ, 2013. - 223 с.

2. Галяутдинова С. И., Ахмадеева Е. В., Гумерова Р. Б. Проблемы понимания ценностей и психологической безопасности семьи. - Уфа, 2014. - 156 с.

3. Дмитриева Л. А. Проблематика исследования психологической безопасности субъекта следственной деятельности: методологический аспект // Расследование преступлений: проблемы и пути их решения. 2015. - № 1 (7). - С. 172-174.

4. Ковдра А. С. Временная перспектива как предиспозиция психологической безопасности личности: дисс. ... канд. психол. наук. - Пятигорск: Институт образовательных технологий, 2012. - 224 с.

5. Краснянская Т. М. Психологическая роль ритуала в самообеспечении безопасности личности: ресурсный подход // Прикладная психология и психоанализ. - 2014. - № 4. - C. 1. - URL: http://ppip.idnk.ru

6. Краснянская Т. М., Тылец В. Г. Визуализация практики самообеспе- 
чения безопасности в приметах и обычаях студентов вуза // Психология и психотехника. - 2015. - № 11. - C. 1158-1166. DOI:10.7256/20708955.2015.11.17018

7. Кудака М. А., Иллензеер О. М. Исследование взаимосвязи уровня развития социального интеллекта с типами отношения к опасностям у людей зрелого возраста // Ученые записки Череповецкого государственного университета. - 2016. - № 1 (5). - С. 6-8.

8. Лызь Н. А., Куповых Ж. Г. Представления о безопасности как предмет эмпирических исследований // Современные научные исследования и инновации. - 2015. - № 8-2 (52). - С. 161-166.

9. Маралов В. Г., Смирнова О. В. Психологические особенности сензитивности к угрозам у студентов вузов // Сборники конференций НИЦ Социосфера. - 2014. - № 63. - С. 36-41.

10. Саввичева Д. Д. Уверенность в себе студентов вуза как личностная детерминанта готовности к рискам нарушения безопасности // Психология, социология и педагогика. - 2016. - № 1 (52). - С. 76-83. - URL: http://psychology.snauka.ru/2016/01/6258

11. Сарма О. В. Субъектные приоритеты безопасности и предпочтения примет среди студентов вуза // Education Sciences and Psychology. 2015. - № 3 (35). - C. 53-57. - URL: http://gesj.internet-academy.org.ge/ download.php?id=2529.pdf

12. Татьянченко Н. П. Психологические условия обеспечения безопасности личности военнослужащих:дисс. ... канд. психол. наук. - Сочи, 2008. - 239 с.

13. Тырсикова А. Д. Формирование стратегий психологической безопасности студентов вуза: дисс. ... канд. психол. наук. - Пятигорск: Пятигорский государственный лингвистический университет, 2012. - 199 с.

14. Brand S., Felner R. D., Seitsinger A., Burns A., Bolton N. A large scale study of the assessment of the social environment of middle and secondary schools: The validity and utility of teachers' ratings of school climate, cultural pluralism, and safety problems for understanding school effects and school improvement // Journal of School Psychology. - 2008. - V. 46. - no. 5. - pp. 507-535.

15. Carmeli A., Brueller D., Dutton J. E. Learning behaviours in the workplace: The role of high-quality interpersonal relationships and psychological safety // Systems Research and Behavioral Science. - 2009. - pp. 81-89.

16. Clarke $S$. The relationship between safety climate and safety performance: A meta-analytic review // Journal of Occupational Health Psychology. 2006. - no. 11 (4). - pp. 315-327.

17. Goldstein S. E., Young A., Boyd C. Relational aggression at school: Associations with school safety and social climate // Journal of Youth and Adolescence. - 2008. - V. 37. - no. 6. - pp. 641-654. 
18. Griffin M. A., Neal A. Perceptions of safety at work: A framework for linking safety climate to safety performance, knowledge, and motivation // Journal of Occupational Health Psychology. - 2000. - no. 5 (3). - pp. 347-358.

19. Krasnyanskaya T. M., Tylets V. G. Fractal Approach to the Interpretation of Psychological Safety of the Person // European Journal of Psychological Studies. - 2015. - V. (6). - Is. 2. - pp. 48-57. DOI:10.13187/ejps.2015.6.48

20. Siemsen E., Roth A. V., Balasubramanian S., Anand G. The influence of psychological safety and confidence in knowledge on employee knowledge sharing // Manufacturing \& Service Operations Management. - 2009. no. 11 (3). - pp. 429-447.

\section{References}

1. Blagodyr' E. M. Psikhologicheskie osobennosti formirovaniya bezopasnogo povedeniya u vospitannikov detskikh domov. Diss. kand. psikh. nauk [Psychological features of the formation of safe behaviour in inmates of a children's home. Cand. psych. sci. diss]. Pyatigorsk, Pyatigorsk State Linguistic University Publ., 2013. 223 p.

2. Galyautdinova S. I., Akhmadeeva E. V., Gumerova R. B. Problemy ponimaniya tsennostei i psikhologicheskoi bezopasnosti sem'i [Problems of understanding values and psychological safety of the family]. Ufa, 2014. 156 p.

3. Dmitrieva L. A. Problematika issledovaniya psikhologicheskoi bezopasnosti sub"ekta sledstvennoi deyatel'nosti: metodologicheskii aspekt [The problem of studying psychological safety of the subject of investigative activities: a methodological aspect]. Rassledovanie prestuplenii: problemy i puti ikh resheniya - Investigation of Crimes: Problems and Ways of Their Solution, 2015, no. 1 (7), pp. 172-174.

4. Kovdra A. S. Vremennaya perspektiva kak predispozitsiya psikhologicheskoi bezopasnosti lichnosti. Diss. kand. psikh. nauk [Time perspective as the predisposition of psychological safety of the person. Cand. psych. sci. diss]. Pyatigorsk, Institute of Educational Technology Publ., 2012. 224 p.

5. Krasnyanskaya T. M. The psychological role of the ritual in self-security of the person: the resource approach. Journal of Applied Psychology and Psychoanalysis, 2014, no. 4. Available at: http://ppip.idnk.ru

6. Krasnyanskaya T. M., Tylets V. G. Vizualizatsiya praktiki samoobespecheniya bezopasnosti v primetakh i obychayakh studentov vuza [Visualization of self-security in omens and customs of students of institutes of higher education]. Psikhologiya i psikhotekhnika - Psychology and Psychotechnics, 2015, no. 11, pp. 1158-1166. doi:10.7256/2070-8955.2015.11.17018

7. Kudaka M. A., Illenzeer O. M. Issledovanie vzaimosvyazi urovnya razvitiya sotsial'nogo intellekta s tipami otnosheniya k opasnostyam u lyudei zrelogo 
vozrasta [Studying the relationship between the level of the development of social intelligence and the types of relations to danger in mature persons]. Uchenye zapiski Cherepovetskogo gosudarstvennogo universiteta - Proceedings of Cherepovets State University, 2016, no. 1 (5), pp. 6-8.

8. Lyz' N. A., Kupovykh Zh. G. Predstavleniya o bezopasnosti kak predmet empiricheskikh issledovanii [Perception of security as a subject of empirical studies]. Sovremennye nauchnye issledovaniya i innovatsii - Modern Scientific Research and Innovations, 2015, no. 8-2 (52), pp. 161-166.

9. Maralov V. G., Smirnova O. V. Psikhologicheskie osobennosti senzitivnosti k ugrozam u studentov vuzov [Psychological features of sensitivity to threats in students of institutes of higher education]. Sborniki konferentsii NITs Sotsiosfera-Conference Proceedings of the Science Publishing Centre "Sociosphere", 2014, no. 63, pp. 36-41.

10. Savvicheva D. D. Uverennost' v sebe studentov vuza kak lichnostnaya determinanta gotovnosti k riskam narusheniya bezopasnosti [Self-confidence in students as the determinant of personal willingness to risks of security breaches]. Psikhologiya, sotsiologiya i pedagogika - Psychology, Sociology and Pedagogy, 2016, no. 1 (52), pp. 76-83.

11. Sarma O. V. Sub"ektnye prioritety bezopasnosti i predpochteniya primet sredi studentov vuza [Subjective priorities of safety and preferences of omens among students of institutes of higher education]. Education Sciences and Psychology, 2015, no. 3 (35), pp. 53-57.

12. Tat'yanchenko N. P. Psikhologicheskie usloviya obespecheniya bezopasnosti lichnosti voennos/uzhashchikh. Diss. kand. psikh. nauk [Psychological conditions of ensuring safety of soldiers. Cand. psych. sci. diss]. Sochi, 2008. 239 p.

13. Tyrsikova A. D. Formirovanie strategii psikhologicheskoi bezopasnostistudentov vuza. Diss. kand. psikh. nauk [The formation of strategies of psychological safety of students of the institute of higher education. Cand. psych. sci. diss]. Pyatigorsk, Pyatigorsk State Linguistic University Publ., 2012. 199 p.

14. Brand S., Felner R. D., Seitsinger A., Burns A., Bolton N. A large scale study of the assessment of the social environment of middle and secondary schools: The validity and utility of teachers' ratings of school climate, cultural pluralism, and safety problems for understanding school effects and school improvement. Journal of School Psychology, 2008, V. 46, no. 5, pp. 507-535.

15. Carmeli A., Brueller D., Dutton J. E. Learning behaviours in the workplace: The role of high-quality interpersonal relationships and psychological safety. Systems Research and Behavioral Science, 2009, pp. 81-89.

16. Clarke $S$. The relationship between safety climate and safety performance: A meta-analytic review. Journal of Occupational Health Psychology, 2006, no. 11 (4), pp. 315-327. 
РОССИЙСКИЙ ПСИХОЛОГИЧЕСКИЙ ЖУРНАЛ • 2016 ТОМ 13 № 4

17. Goldstein S. E., Young A., Boyd C. Relational aggression at school: Associations with school safety and social climate. Journal of Youth and Adolescence, 2008, V. 37, no. 6, pp. 641-654.

18. Griffin M. A., Neal A. Perceptions of safety at work: A framework for linking safety climate to safety performance, knowledge, and motivation. Journal of Occupational Health Psychology, 2000, no. 5 (3), pp. 347-358.

19. Krasnyanskaya T. M., Tylets V. G. Fractal Approach to the Interpretation of Psychological Safety of the Person. European Journal of Psychological Studies, 2015, V. (6), Is. 2, pp. 48-57. DOI:10.13187/ejps.2015.6.48

20. Siemsen E., Roth A. V., Balasubramanian S., Anand G. The influence of psychological safety and confidence in knowledge on employee knowledge sharing. Manufacturing \& Service Operations Management, 2009, no. 11 (3), pp. 429-447. 